\title{
ASSESSING INTER-SEASONAL VARIATIONS OF VEGETATION COVER AND LAND SURFACE TEMPERATURE IN THE NCR USING MODIS DATA
}

\author{
MALlick, J. $^{1 *}$ - HANG, T. H. ${ }^{2}-$ RAHMAN, A. $^{2}-$ HASAN, M. A. ${ }^{1}-$ IBRAHIM, F. ${ }^{1}-$ AHMED, M. ${ }^{1}$ \\ ${ }^{1}$ Department of Civil Engineering, College of Engineering, King Khalid University, Abha, \\ Saudi Arabia \\ ${ }^{2}$ Urban Environmental \& Remote Sensing Division, Faculty of Natural Sciences, Jamia Millia \\ Islamia, New Delhi, India \\ *Corresponding author \\ e-mail: jmallick@kku.edu.sa; phone: +966-17-241-8171; fax:+966-17-241-8816
}

(Received 22 ${ }^{\text {nd }}$ Nov 2019; accepted 24 ${ }^{\text {th }}$ Mar 2020)

\begin{abstract}
Complex land use/land cover (LULC) patterns were investigated in the National Capital Region, India (NCR). India have a major impact on prevailing surface temperature circumstances. Various studies have been undertaken to establish the relationship between Normalized Difference Vegetation Index (NDVI) and land surface temperature (LST) in various geographic regions and ecosystems over the past two decades. However, studies aiming to understand the seasonal variation of environmental conditions, especially the thermal environment at the regional level are missing in NCR. This study employs MODIS satellite imagery to assess the temporal relationship between land surface temperature mechanics for LULC and vegetation cover in the NCR over five seasons. Results showed that concerning the scrubland/fallow land areas and agricultural land, the difference between the maximum and minimum temperature is the highest for all seasons, largely corresponding to NCR Cities' peripheral areas. The LST plays a significant role in NDVI related to vegetation vigour and growth in the NCR. The study shows that the seasonal distribution of LST needs to be overcome with high vegetation cover and some other appropriate mitigation measures.
\end{abstract}

Keywords: thermal environment, LULC, NDVI, urban heat islands, Delhi

\section{Introduction}

Urbanisation has led to large scale changes on the Earth's surface, and land surface temperature is one of them. Owing to the transformation of vegetation and agricultural lands into built-up areas, rural and suburban areas are converted into impermeable surfaces, thereby altering both the surface temperature and the atmospheric temperature. With increasing concretization and associated changes in land use/land cover (LU/LC) in urban areas, land temperature patterns have changed which lead to the development of different microclimates in cities and towns (Singh et al., 2012). Motor vehicles, industries, air conditioning and other city lifestyle activities add additional heat to nearby areas (Valsson and Bharat, 2009). Therefore, hightemperature islands develop in some urban areas called urban heat islands (UHIs), whereas relatively cool suburbs are noticed. Reducing the green cover and increasing the built-up area (impervious surface) contribute to the increase of urban heat island (UHI) phenomenon in the cities which leads to the deterioration of the quality of environment in the urban area (Tongliga et al., 2016). According to the 2011 Census of India, 833 million (68.84\%) of the 1.21 billion Indians live in rural areas, while 377 million $(31.16 \%)$ live in urban areas. In India, urbanization rose from $27.81 \%$ in 2001 to $31.16 \%$ in 2011 . Further, $42.6 \%$ urban populations live in 53 metropolitan cities of 
India. The four largest cities of India, i.e. Mumbai, Kolkata, Delhi and Chennai together account for about $15.4 \%$ of India's urban population. In the NCR (sub-region Haryana, UP, Rajasthan and NCT-Delhi) the urban population increased from $50.2 \%$ in 1991 to $62.5 \%$ in 2011, although the NCR rural population decreased from $49.8 \%$ (1991) to $37.5 \%$ (2011).

The data of urban population shows that there is an increasing trend in the urban population. So, to accommodate these people in urban areas, the city needs more housing and other related activities, such as educational, commercial and recreation, etc. This leads to an increase in the built-up areas and with this the land surface temperature (LST) is bound to increase which is the indicator of the thermal environment of urban areas. An urban area's LST is influenced by many factors such as season, daytime, topography, clouds, wind, rural environment, location, land use, city-building materials and geometry (Valsson and Bharat, 2009). The LST has an indirect but significant impact on air temperatures, in particular, the canopy layer near to the ground. (Mallick et al., 2008). The vegetated areas act as the city's lungs and contribute to temperature control (Owen et al., 1998). In contrast water, soil and vegetation are replaced by impermeable asphalt, concrete and hard rock surfaces in urban areas, which has environmental consequences, including a decrease in evapotranspiration, high rainfall-runoff and increased surface temperatures, which leads to a deterioration of the general urban and thermal environment (Owen et al., 1998).

Because of their importance to regional climate, quality of life, urban air quality, land use/land cover (LULC) transition and urban carbon emission situation have been studied extensively in the last two decades worldwide namely, Houston (Streutker, 2003), Salt lake valley (Gluch et al., 2006), Lahore (Ali and Nitivattananon, 2012), Wisconsin (Deng and Wu, 2013), Faislabad (Shabana et al., 2015), Baotou (Tongliga et al., 2016), Bangkok (Ali et al., 2017), the NCR, India (Hang et al., 2018). Research on the urban thermal environment has gained importance in the Indian scenario over the last decade (Mallick et al., 2008; Pandey et al., 2012; Chakraborty et al., 2013; Mallick et al., 2013; Mathew et al., 2016; Hang et al., 2018; Kumari et al., 2018).

The land surface temperature also varies with the changing seasons over different LU/LC (Deng et al., 2013). The land surface temperature magnitude varies with the seasons due to changes in ground cover, sun intensity, and weather conditions. Due to this variation, the terrestrial surface temperature is typically higher in the summer than in winter (Oke, 1982). Research on the seasonal comparison of the urban thermal environment has been carried out by various scholars, e.g. Pandey et al. (2009) examined UHI for day-night conditions in Delhi during the summer, Li et al. (2012) studied Shanghai's seasonal changes in UHI. Mallick et al. (2013) investigated the spatial and temporal variation in land surface temperature strongly associated with the impermeable surface area (ISA) to study the effects of urbanization on the spring season of the NCT-Delhi and Weng and Yang (2004) examined the adverse thermal effects of urban development in Guangzhou, China, during the summer and winter seasons. While Streutker (2003) studied the land surface temperature for Houston seasonal UHI analysis, Zhang et al. (2013) used Landsat data. Nevertheless, studies to understand the seasonal variation of environmental conditions, especially regarding the thermal environment at regional level lacks in India.

Normalized Difference Vegetation Index (NDVI) and LST are crucial to understand the relationships between terrestrial ecosystems and the climate system in 
an environmentally sensitive area. Research on the relationship between LST and NDVI (Zhang et al., 2013) helps to understand the factors that cause environmental deterioration, significant changes in the carbon cycle of the land-based environment and highlights the mechanisms that control land carbon storage response to climate variability (Braswell et al., 1997). Several studies have undertaken to establish the relationship between NDVI and LST in various ecosystems and geographic regions over the past two decades. However, vegetation response mechanisms to temperature are still unclear (Weng, 2003). Some of these studies relates explicitly to the change in NDVI and LST as factors or examined their spatial changes during the growing season (Schultz and Halpert, 1995; Pottar and Brooks, 1998). However, there are no studies in the NCR region that focus on NDVI and LST in different seasons. It is therefore essential to study the variation in the vegetation cover and the relationship between NDVI and LST in the area.

With this background of the factual issue and lack of research into inter-seasonal variations in the thermal environment, in particular in the NCR, India, this study is extremely important. The objective of this paper is, therefore, to analyse the temporal relationship between land surface temperature mechanics for land use/land cover and vegetation cover (NDVI) in the National Capital Region (NCR) over five seasons.

\section{Materials and methods}

The details of data sets from different sources used in this study related to the NCR, India are given below:

(a) Moderate Resolution Imaging Spectroradiometer (MODIS) NDVI 16-day composite raster data L3 product (MOD13Q1) with the spatial resolution of $250 \mathrm{~m}$ (4800 rows $\times 4800$ columns) in HDF format was acquired from the NASA Earth Observation System (EOS) data gateway (https://earthexplorer.usgs.gov/) for January 2016 to December 2016. MODIS is the main instrument onboard the Aqua and Terra satellites, which view the entire surface of the Earth every 1 to 2 days and collect data from $0.4 \mathrm{~mm}$ to $14.4 \mathrm{~mm}$ in 36 discrete spectral bands. This information has improved our knowledge of global dynamics in land, oceans and the lower atmosphere (Ren et al., 2008). MODIS has the potential of spectral and spatial resolutions higher than NOAA/AVHRR and spectral and temporal resolutions higher than SPOT or Landsat TM. Since MODIS data are collected in a narrow spectrum, the effect of water vapour absorption in the NIR band is minimized the red band data is much more sensitive to chlorophyll, thus improving the quality of NDVI data (Huete et al., 2002; Van et al., 1999). Consequently, MODIS NDVI was widely used in vegetation classification (Wardlow et al., 2007), vegetation phenology (Beck et al., 2006), LULC change (Lunetta et al., 2006) and crop mapping (Xiao et al., 2005) etc.

(b) MODIS LST level-3 data (MOD11A2 L3) with $1000 \mathrm{~m}$ spatial resolution available in every eight days in HDF format with 1200 rows $\times 1200$ columns were downloaded from the NASA Earth Observation System (EOS) data gateway (https://earthexplorer.usgs.gov/) from January 2016 to December 2016.

(c) Field visit and Google Earth data were used in the study area to analyze, validate and monitor land use.

The detail of the methodological procedure for the analysis of various data set has been discussed below. 


\section{(a) Creation of base layers}

Base layers such as the NCR sub-regions, India, district boundaries, roads, water bodies etc. were created at a scale of 1:50000 from SOI toposheets.

In this study, in the NCR region the year is divide up into five seasons: winter, spring, summer, monsoon, and autumn. Each season lasts 2-3 months with summer being the warmest season, winter being the coldest, monsoon being the rainiest, and spring and autumn lie in between of winter and summer. Winter season is in December and January, spring season is in February and March, summer season is in April, May, June, monsoon season is in July, August and September and autumn season is in October and November

\section{(b) MODIS NDVI data georeferencing}

MODIS NDVI data were projected to UTM WGS84 and resampled to a $250 \mathrm{~m}$ grid cell, followed by layer stack and subsetting of the region of interest (ROI).

\section{(c) MODIS LST data georeferencing}

MODIS LST data were projected to UTM WGS84, followed by subsetting of the study area. These MODIS data of $1000 \mathrm{~m}$ bands were resampled to a $250 \mathrm{~m}$ grid in accordance with MODIS NDVI bands using the nearest neighbourhood technique. NDVI layer is a 16-bit signed integer with a fill value of -3000 and a valid range of 2000 to 1000 . However, there is a 0.0001 or $1 / 10000$ scale factor. This explains that a value of 10,000 in the raster should be multiplied by 0.0001 to reach the real data value.

\section{(d) Computation of LST from MODIS LST bands}

MODIS Land Surface Temperature/Land Surface Emissivity (LST/LSE) data were multiplied by a scale factor of 0.02 or $2 / 100$. This means that an LST value in the raster should be multiplied by 0.02 to reach the actual data value.

\section{(e) Computation of monthly and seasonal NDVI}

Daily images have been composed in semi-monthly span (two per month, from the first day of the month to the fifteenth and from the sixteenth to the end of the month) using the NDVI of maximum value recorded. Instead of the average semi-monthly periods, maximum NDVI values were used to ensure the minimum effect on our data of any remaining cloud coverage. Whereas seasonal NDVI was obtained using mean NDVI for a specific seasonal period.

\section{(f) LULC map}

LULC map was generated using LANDSAT-8 and resampled to a $250 \mathrm{~m}$ grid in accordance with MODIS NDVI bands using the nearest neighbourhood technique. The eight LULC classes were made based on the NRSC classification scheme of 1996 agricultural cropland, built-up land, water bodies, scrubland and fallow land, bare soil and exposed rocks and vegetation. An extensive field survey was carried out to collect the information of land cover during the months of April to May 2016 (cloud-free date). The locations of the samples were recorded using a handheld global positioning system (GPS) with an accuracy of less than $5 \mathrm{~m}$. 


\section{(g) Analysis of seasonal pattern/trend}

The statistics of surface temperature and NDVI by LU/LC types were obtained by overlaying LU/LC map with LST, and NDVI. In order to evaluate their distribution in different seasons (autumn, summer, monsoon, spring and winter), NDVI and LST data from the LU/LC class were analyzed.

\section{(h) Statistical analysis}

Statistical analysis is performed to evaluate the seasonal relationship between NDVI, LST and LULC data.

\section{Results and discussion}

MODIS NDVI and LST data have been used to produce monthly NDVI and monthly LST maps. Detailed literature of the MODIS NDVI composite process and the Science Data Sets for Quality Assessment (QASDS) can be found on the MODIS website of NASA (MODIS, 1999) and the same has been used in the analysis. Similarly, the guide for the generation of data, data attributes and quality assurance details could be found in MODIS LST products user and is used in the chapter. The LST maps have been calibrated and validated from previous NOAA data records (http://gis.ncdc.noaa.gov/map/viewer).

\section{Monthly and seasonal vegetation density (NDVI) analysis}

The rural-agricultural area of the NCR is getting urbanized and industrialized, with which the vegetation cover is significantly changing and also leads to an increase in pollution in the region. The NDVI is an important parameter that provides information on the vigour and growth of vegetation in any area or region. It is one of the land's greenery representations that also provides information on the type of vegetation, growth rate and water demand and also helps to study the environmental condition of regions. The NDVI is a sensitive parameter that provides information on vegetation growth and helps predict environmental change in any region. Singh et al. (2003) regarded NDVI as an important parameter in the assessment of the impact of drought. In order to better understand the dynamic nature of NDVI, seasonal variability of NDVI and its effect on meteorological parameters in NCR has been studied in this paper.

\section{Season-wise vegetation density (NDVI) analysis using MODIS NDVI}

In this part of the thesis seasonal changes in spatial pattern of NDVI are examined in relation to general pattern of LU/LC using NDVI maps (Fig. 1) extracted for the five seasons (i.e. winter season, spring season, summer season, monsoon season and autumn season) from the MODIS NDVI (MOD13Q1). The overall understanding of LU/LC information was derived from the Landsat-8, Google Earth and field survey done during January to February 2016.

The seasonal spatial distribution of NDVI shows that the lowest mean NDVI values (0.284) were recorded in the summer season (Fig. 1) i.e. in April, May, June. The climatic factors such as precipitation, solar radiation and land without crops are some of the limiting factors for low NDVI value (Fig. 1). 


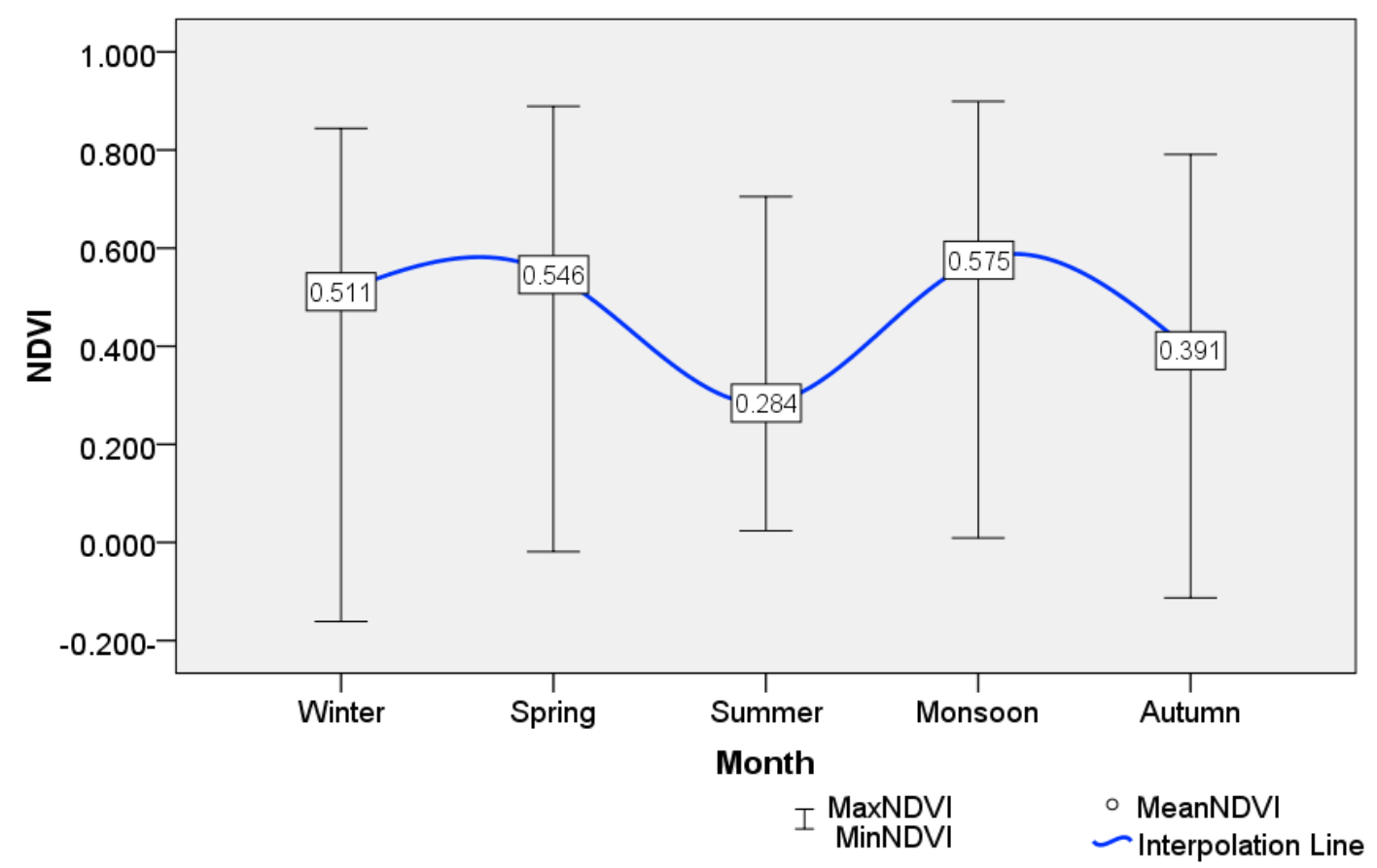

Figure 1. The seasonal variation of NDVI during 2016

Lower NDVI values $(<0.2)$ were observed in the maximum areas of NCR except in the Ganga-Yamuna river basin areas (Eastern and north-eastern part of NCR) and patched with ridge forest area that could be observed in Delhi-NCT, southern NCR near Alwar. During summer the shortage of water, agricultural cropland and high thermal intensity are responsible for the lower NDVI values across the NCR. The lowest NDVI values of the summer season are observed in the bare soil and exposed rocks (BSER), the values range between 0.177 and 0.288 with a mean NDVI of 0.258 and a standard deviation (STD) of 0.056 (Table 1). The highest NDVI values are notified in the vegetation (VEG) ranging from 0.223 to 0.689 with a mean NDVI of 0.384 and an STD of 0.097 . The highest standard deviation is found over water bodies due to the pixel mixed with vegetated areas (as a limitation of MODIS data because of too low spatial resolution).

The seasonal variation of NDVI suggests that the lowest mean NDVI values $(0.391)$ were recorded in the autumn season (Fig. 3), i.e. October and November, which is the beginning of the winter season. This is due to the stop of photosynthesis when autumn arrives, the leaves lose chlorophyll, change colour and eventually fall. The variation of NDVI during the autumn season is shown in Figure 3.

The lower NDVI values were observed in the central, north-western parts of the study area, which are mainly covered by built-up land, fallow land and bare soil (Fig. 2). The eastern and north-eastern part of NCR, i.e. Ganga-Yamuna Basin areas and the rocky ridge of Aravali hills in Delhi-NCT and southern NCR region (near Alwar) with linear stretch from south to northeast directions show the highest NDVI values. The lowest NDVI was found over the build-up land with a mean of 0.208 and standard deviation of 0.049 whereas, the highest NDVI is observed over vegetation located toward the southern part of NCR, i.e. in the ridge forest.

December and January are the coldest months of the year, and in these months the highest and lowest NDVI values are -0.161 and 0.844 with the mean of 0.511 . The 
lowest NDVI values were noticed in the central parts of the study area, primarily covered by urban and rural built-up areas. In the north, west and south-east part of the study area, high NDVI values were notified. This is due to the cultivation of "Ravi" agricultural crops in these areas. Table 1 shows the statistics of NDVI of the winter season. The higher NDVI values found over the agricultural cropland of the mean value of 0.624 , whereas the lower NDVI values could be seen over the built-up areas. Moderate NDVI value was found over the vegetated land due to topical deciduous characterizes.

In the entire study area, overall high NDVI were recorded in the spring season compared to winters (Fig. 2). The NDVI value pattern, however, is similar to the winter season except for the ridge forest areas. During, spring season the highest and lowest NDVI values were -0.19 and 0.889 with the mean of 0.546 . Lower NDVI values are recorded in the central and south-western parts of NCR, which are dominated by builtup and bare soil/exposed rocks. There is a moderate value of NDVI found over the surrounding of Delhi-NCT which corresponds to fallow land. There were also few patches to the southern part of the NCR. During the spring season, the NDVI over different LULC is shown in Table 1. The maximum NDVI value is shown in agricultural cropland with an average NDVI value of 0.523 and a STD of 0.062 . The minimum NDVI found over built-up land with a mean NDVI of 0.206 and a STD of 0.073 .

Table 1. Statistics of NDVI over different LULC during different seasons in 2016

\begin{tabular}{c|c|c|c|c|c|c|c}
\hline Seasons & Properties & AGRI & BL & WB & SLAF & BSER & VEG \\
\hline \multirow{5}{*}{ Winter season } & Minimum NDVI & 0.500 & 0.040 & 0.198 & 0.324 & 0.268 & 0.220 \\
& Maximum NDVI & 0.753 & 0.445 & 0.488 & 0.548 & 0.608 & 0.674 \\
& Mean NDVI & $\mathbf{0 . 6 2 4}$ & $\mathbf{0 . 1 8 3}$ & $\mathbf{0 . 3 5 0}$ & $\mathbf{0 . 3 4 0}$ & $\mathbf{0 . 3 2 1}$ & $\mathbf{0 . 3 9 8}$ \\
& Standard deviation & 0.062 & 0.065 & 0.098 & 0.075 & 0.069 & 0.800 \\
\hline \multirow{5}{*}{ Spring season } & Minimum NDVI & 0.368 & 0.076 & 0.189 & 0.234 & 0.205 & 0.203 \\
& Maximum NDVI & 0.630 & 0.595 & 0.516 & 0.405 & 0.426 & 0.683 \\
& Mean NDVI & $\mathbf{0 . 5 2 3}$ & $\mathbf{0 . 2 0 6}$ & $\mathbf{0 . 3 5 7}$ & $\mathbf{0 . 3 5 7}$ & $\mathbf{0 . 3 0 9}$ & $\mathbf{0 . 4 7 8}$ \\
& Standard deviation & 0.062 & 0.073 & 0.105 & 0.036 & 0.041 & 0.101 \\
\hline \multirow{5}{*}{ Summer season } & Minimum NDVI & 0.380 & 0.090 & 0.139 & 0.146 & 0.177 & 0.223 \\
& Maximum NDVI & 0.541 & 0.440 & 0.503 & 0.354 & 0.288 & 0.689 \\
& Mean NDVI & $\mathbf{0 . 4 3 8}$ & $\mathbf{0 . 2 1 1}$ & $\mathbf{0 . 3 2 0}$ & $\mathbf{0 . 2 9 7}$ & $\mathbf{0 . 2 5 8}$ & $\mathbf{0 . 3 8 4}$ \\
& Standard deviation & 0.043 & 0.058 & 0.135 & 0.047 & 0.056 & 0.097 \\
\hline & Minimum NDVI & 0.507 & 0.123 & 0.094 & 0.307 & 0.242 & 0.411 \\
& Maximum NDVI & 0.755 & 0.422 & 0.567 & 0.675 & 0.478 & 0.847 \\
& Mean NDVI & $\mathbf{0 . 6 2 1}$ & $\mathbf{0 . 2 8 7}$ & $\mathbf{0 . 3 7 6}$ & $\mathbf{0 . 4 8 8}$ & $\mathbf{0 . 4 0 8}$ & $\mathbf{0 . 6 2 5}$ \\
& Standard deviation & 0.049 & 0.100 & 0.183 & 0.056 & 0.036 & 0.082 \\
\hline \multirow{5}{*}{ Autumn season } & Minimum NDVI & 0.383 & 0.082 & 0.117 & 0.213 & 0.346 & 0.282 \\
& Maximum NDVI & 0.542 & 0.297 & 0.407 & 0.476 & 0.478 & 0.698 \\
& Mean NDVI & $\mathbf{0 . 4 7 5}$ & $\mathbf{0 . 2 0 8}$ & $\mathbf{0 . 3 0 3}$ & $\mathbf{0 . 3 7 6}$ & $\mathbf{0 . 4 2 1}$ & $\mathbf{0 . 4 7 3}$ \\
& Standard deviation & 0.036 & 0.049 & 0.107 & 0.046 & 0.033 & 0.081 \\
\hline
\end{tabular}

AGRI = agricultural cropland; $\quad \mathrm{BL}=$ builtup land; $\mathrm{WB}=$ waterboides; $\quad \mathrm{SLFL}=$ scrubland and fallowland; BSER = bare soil and exposed rocks; VEG = vegetation 


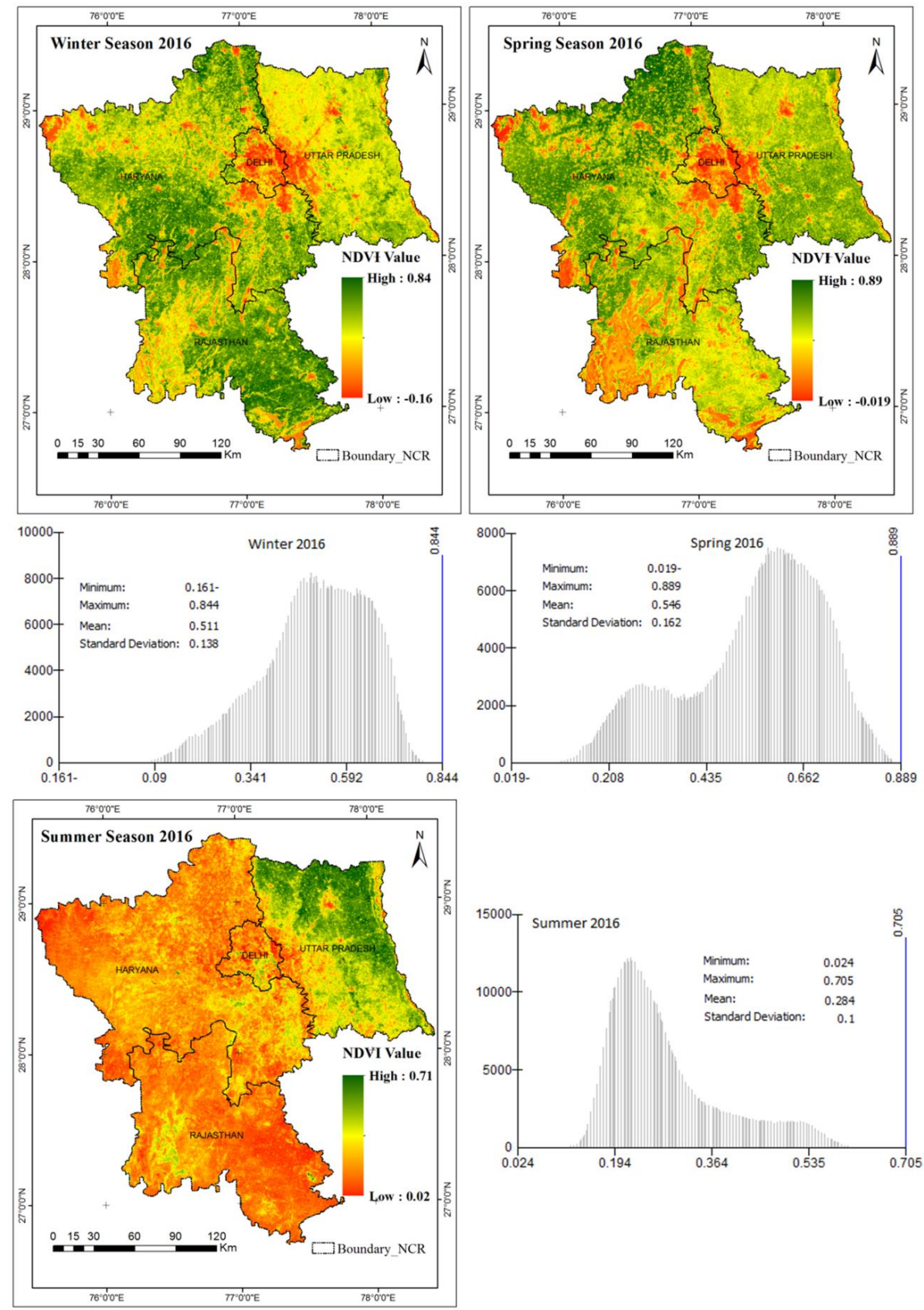

Figure 2. Spatial distribution of seasonal average NDVI during winter, spring and summer with their histogram (frequency) in 2016

The monsoon season (July, August and September) is dominated by rainfall, higher temperature and high humidity and because of this, the highest NDVI value (0.575) is recorded in this season. However, low NDVI values are spatially limited to areas built up throughout the city (Delhi, Ghaziabad, Gurgaon, Meerut, Rewari, etc.). Due to builtup areas are concrete and asphalt-dominated surfaces that do not maintain long-term moisture this minimized the NDVI value. During monsoons when most part of the cities has plenty of moisture, the impermeable areas are still largely free of moisture and such surfaces emerge as low NDVI areas. In monsoon and post-monsoon season, temperatures fall sharply and the pattern of NDVI distribution changes significantly. 
The land cover ridge forests (i.e. near Delhi, near Alwar) and other forest patches show higher NDVI. The north-western, western, central and south-eastern parts of the NCR, which are predominantly scrubland/fallow land, built-up and barren land, have the lowest NDVI values (Fig. 3). It is important to note that in the summer season, areas with the lowest NDVI value experienced the high NDVI in monsoon due to increased greenness. During the monsoon season, the NDVI over different LULC is shown in Table 1. Low NDVI values were shown in built-up land with an average NDVI of 0.287 and high NDVI values were found over the vegetated surfaces, ranging between 0.411 to 0.847 with the mean value of 0.625 and a STD of 0.082 . The vegetated and agricultural cropland (Kharif crops) that dominates the eastern, north and surrounding the urban peripheries show high NDVI values.

\section{Season-wise surface temperature analysis using MODIS LST}

Agricultural cropland cultivated in the NCR is approximately $1271.5 \mathrm{~km}^{2}$, which is concentrated mainly in Yamuna, Hindon, Kali and Ganga rivers forming Ganga-Yamuna basin areas. The agricultural land (fallow land) is left barren during the summer months, while different crop varieties are grown depending on the season during the rest of the year. Agriculture is also practiced along the Yamuna, Hindon, Kali and Ganga rivers etc. because of this, it divides the study area into two parts, the east (Ganga-Yamuna basin areas) and west semi and Arid land. Between these two areas, there was a buffer zone which could be clearly seen in the summer season on LST maps (Fig. 4). The water bodies (i.e. rivers, lakes, ponds and water tanks) can be observed in the north, east and central part in the NCR and cover a very small area, i.e. $257 \mathrm{~km}^{2}$. Healthy forests and tree cover is mostly located in the central and eastern part of the NCR. The forest types are the dry deciduous forests and the predominant trees as per Forest Survey of India (FSI, 2000) are Teak, Sal, Rosewood, Satinwood, Bel, Khair, kiker, Dhok, Asan, Bamboo, Bahera, Raunj, Salar, Ber, Jhighan, and Thor etc. According to the Forest Survey of India (FSI) estimates (2011), forest and tree cover account for approximately $7.6 \%$ of the total area of the NCR. As per our LULC map 2016, the dense vegetation and sparse vegetation covers approximately $10 \%$ of the total area of the NCR.

The seasonal variation of LST shows that the lowest surface temperature was recorded in the winter season (Fig. 5), i.e. in December and January, which are the coldest months of the year. In winters (December-January), LST ranges between 19.28 ${ }^{\circ} \mathrm{C}$ and $31.35{ }^{\circ} \mathrm{C}$ with a mean of $23.87{ }^{\circ} \mathrm{C}$. The distribution of the lowest temperature ranges between 19.28 to $23.49{ }^{\circ} \mathrm{C}$, which could be observed in the central, northeastern, eastern, central-southern and some pockets towards the southern parts of the study area, mainly covered by agricultural land (under the Rabi crop), sparse and dense vegetation, and rural development. The water bodies, including lakes and ponds, are well distributed in the study area, mainly the Yamuna river stretches, and Ganga river stretches, dominate the peripheral areas where very low land surface temperature range is recorded (19.28-22.5 $\left.{ }^{\circ} \mathrm{C}\right)$. The rocky ridge of Aravali hills in southern NCR with linear stretch from south to north and east directions with some forest patches also shows the lowest land surface temperature range $\left(23-26^{\circ} \mathrm{C}\right)$. The highest temperature of the winter season is observed on the bare soil and exposed rocks which range between 23.74 and $27.33{ }^{\circ} \mathrm{C}$ with a mean land surface temperature of $25.19{ }^{\circ} \mathrm{C}$ and a STD of 0.800 (Table 2). LST of more than $27^{\circ} \mathrm{C}$ could be observed towards the western side of Bhiwani, Narnaul, and Alwar, some land patches which were under construction and development activities in Gurgaon, Faridabad and Ghaziabad $\left(24-27^{\circ} \mathrm{C}\right)$. The urban 
land which is mainly in the central-eastern parts of cities shows moderate temperature conditions ranging between 23 to $25^{\circ} \mathrm{C}$. The built-up rural land is similar to the built-up urban land but having lower land surface temperature compared to the big urban area, which may be due to the densely built-up land in the areas (Fig. 4).

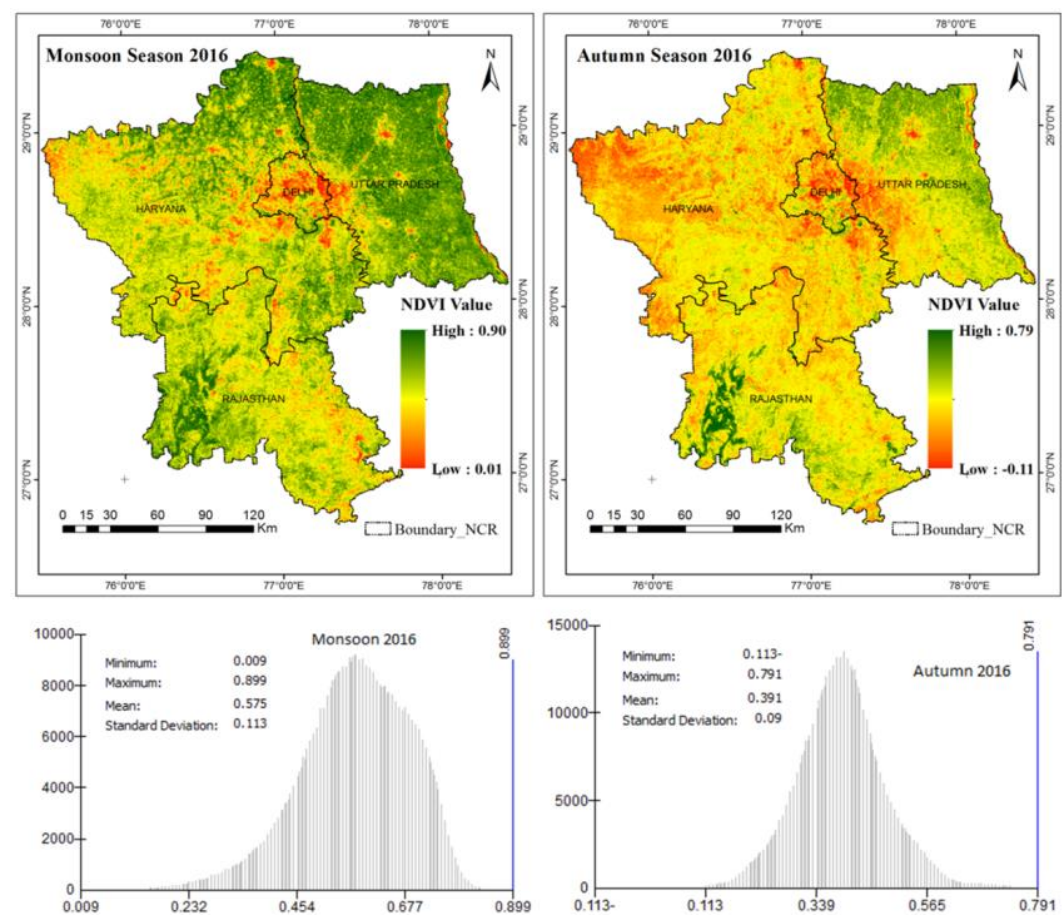

Figure 3. Spatial distribution of seasonal average NDVI during monsoon and autumn with their histogram (frequency) in 2016

In all parts of the study area, the high temperature was recorded in the spring season compared to winter (Fig. 5). The LST pattern, however, is similar to the winter season. During the spring season, LST ranges between 25.8 and $42.91{ }^{\circ} \mathrm{C}$ with a mean of 32.62 ${ }^{\circ} \mathrm{C}$. The spatial distribution of lower temperature ranges between 26 to $32{ }^{\circ} \mathrm{C}$ which could be observed in north, northeast and eastern parts of the NCR. These are the vegetated areas, dominated by agriculture, in Ganga-Yamuna. In the spring season, the temperature of the water bodies is higher than in the winter season $\left(27-33{ }^{\circ} \mathrm{C}\right)$. There is a moderate temperature $\left(31-35^{\circ} \mathrm{C}\right)$ in urban land that dominates central, patches in Ganga-Yamuna river basin areas and eastern NCR. The agricultural fallow lands, bare soils, open areas and parts of built-up urban land in Gurgaon, southeast: south Delhi and airport's open area of NCT-Delhi record this season's highest temperatures (Fig. 4). During the spring season, the LST over different LULC is shown in Table 2. The maximum LST is shown in scrubland and agricultural fallow land with an average land surface temperature of $36.05{ }^{\circ} \mathrm{C}$ and a STD of 1.082 and minimum over water bodies between 27.41 and $33.54{ }^{\circ} \mathrm{C}$ with a mean land surface temperature of $30.68{ }^{\circ} \mathrm{C}$ and a STD of 2.280. During the daytime, due to its high thermal inertia and convection and turbulence (e.g. wave action), water tended to warm up slowly. Moreover, characteristics of rivers, canals, ponds and suspended particulates mixed in water bodies, their soil temperature values vary, resulting in a high standard deviation value of 2.280 over water bodies. 
Table 2. Land surface temperature over different LULC during different seasons in 2016

\begin{tabular}{|c|c|c|c|c|c|c|c|}
\hline Seasons & Properties & AGRI* & BL* & WB* & SLFL* & BSER* & VEG* \\
\hline \multirow{4}{*}{ Winter season } & Minimum temp ${ }^{\circ} \mathrm{C}$ & 21.56 & 21.80 & 19.69 & 22.12 & 23.74 & 20.75 \\
\hline & Maximum temp ${ }^{\circ} \mathrm{C}$ & 22.88 & 26.00 & 22.80 & 30.48 & 27.33 & 24.61 \\
\hline & Mean temp ${ }^{\circ} \mathbf{C}$ & 22.02 & 23.30 & 21.22 & 24.04 & 25.19 & 22.82 \\
\hline & Standard deviation & 0.381 & 0.769 & 1.323 & 1.238 & 0.689 & 0.800 \\
\hline \multirow{4}{*}{ Spring season } & Minimum temp ${ }^{\circ} \mathrm{C}$ & 29.62 & 30.91 & 27.41 & 32.86 & 31.26 & 27.78 \\
\hline & Maximum temp ${ }^{\circ} \mathrm{C}$ & 33.08 & 36.94 & 33.54 & 38.27 & 38.03 & 35.45 \\
\hline & Mean temp ${ }^{\circ} \mathbf{C}$ & 31.38 & 33.38 & 30.68 & 36.05 & 34.62 & 32.41 \\
\hline & Standard deviation & 0.772 & 0.787 & 2.280 & 1.082 & 1.176 & 1.815 \\
\hline \multirow{4}{*}{ Summer season } & Minimum temp ${ }^{\circ} \mathrm{C}$ & 35.27 & 38.19 & 34.33 & 46.06 & 40.15 & 33.82 \\
\hline & Maximum temp ${ }^{\circ} \mathrm{C}$ & 39.49 & 44.14 & 42.18 & 51.77 & 48.06 & 42.91 \\
\hline & Mean temp ${ }^{\circ} \mathrm{C}$ & 37.29 & 40.50 & 38.20 & 49.86 & 43.28 & 38.90 \\
\hline & Standard deviation & 0.924 & 1.051 & 3.234 & 1.237 & 1.521 & 1.831 \\
\hline \multirow{4}{*}{ Monsoon season } & Minimum temp ${ }^{\circ} \mathrm{C}$ & 30.56 & 32.49 & 28.97 & 34.70 & 27.40 & 29.60 \\
\hline & Maximum temp ${ }^{\circ} \mathrm{C}$ & 33.00 & 37.44 & 32.09 & 39.75 & 34.99 & 35.09 \\
\hline & Mean temp ${ }^{\circ} \mathbf{C}$ & 31.79 & 34.69 & 30.64 & 36.80 & 30.50 & 31.49 \\
\hline & Standard deviation & 0.488 & 0.809 & 1.182 & 0.892 & 1.299 & 1.232 \\
\hline \multirow{4}{*}{ Autumn season } & Minimum temp ${ }^{\circ} \mathrm{C}$ & 28.46 & 29.98 & 26.45 & 35.66 & 27.62 & 26.93 \\
\hline & Maximum temp ${ }^{\circ} \mathrm{C}$ & 31.86 & 33.63 & 30.35 & 38.98 & 35.40 & 33.03 \\
\hline & Mean temp ${ }^{\circ} \mathrm{C}$ & 30.58 & 31.34 & 28.23 & 37.58 & 32.11 & 29.92 \\
\hline & Standard deviation & 0.883 & 0.571 & 1.597 & 0.735 & 1.494 & 0.987 \\
\hline
\end{tabular}

AGRI = agricultural cropland $; \quad \mathrm{BL}=$ builtup land; $\mathrm{WB}=$ waterboides; $\quad \mathrm{SLFL}=$ scrubland and fallowland; BSER = bare soil and exposed rocks; VEG = vegetation

The present study shows that during the summer season, the temperature rises sharply and the pattern of variation of surface temperatures significantly changes. Only water bodies (drains, river Ganga, river Yamuna and lakes), ridge forests and other forest patches record lower temperatures $\left(34-41{ }^{\circ} \mathrm{C}\right)$. The vegetation cover serves as sinks for heat and plays a significant role in mitigating the local and neighbouring environment, thus regulating the extreme heating of the areas concerned as also reported by Yuan and Bauer (2009) and Singh et al. (2014). The south-eastern, north-western and eastern and parts of the NCR, which are predominantly scrubland/fallow land, built-up and barren land, have the highest land surface temperature which ranges between 45 and $52{ }^{\circ} \mathrm{C}$ ). It is important to note that areas with the highest summer temperature experienced the lowest winter temperature. There is also intense heating in the over open and barren land of NCT-Delhi nearby the IGI airport where about some time $48{ }^{\circ} \mathrm{C}$ temperature is recorded. More than 44 ${ }^{\circ} \mathrm{C}$ LST is observed in the open areas of NCT-Delhi airport and also in some patches which were under construction and development activities. The land surface temperature magnitude varies with the seasons (winter to summer) due to changes in ground cover, sun intensity, and weather conditions. Due to this variation, the terrestrial surface temperature is typically higher in the summer than in the winter (Oke, 1982). During the summer season, the highest and lowest temperatures were 
$33.66{ }^{\circ} \mathrm{C}$ and $51.93{ }^{\circ} \mathrm{C}$ with the mean of $44.35{ }^{\circ} \mathrm{C}$ (Fig. 4). Table 2 provides details of the highest and lowest temperature associated with each type of land use/land cover.

The monsoon season (July, August and September 1st half) is dominated by rainfall and high air humidity. The third highest land surface temperature has been observed during the monsoon season $\left(13.8^{\circ} \mathrm{C}\right)$. This is because the monsoon season has the highest rainfall. However, high land surface temperature values are spatially limited to build up areas almost in every city (Delhi, Ghaziabad, Gurgaon, Meerut, Rewari, etc.). This is due to the incoming short-wave incident at the rural site, which is higher during the monsoon (Fig. 6), perhaps because the urban area is a continuous source of high anthropogenic emissions of aerosols and low urban albedo. This is also because built-up areas are concrete and asphalt-dominated surfaces that do not maintain moisture for long term. During monsoons, when most of the land surfaces have plenty of moisture, the impermeable areas are still largely free of moisture, and such surfaces emerge as high land surface temperature areas with high intensity. In monsoon and post-monsoon season, temperatures fall sharply and the pattern of spatial temperature distribution changes significantly. The land cover, the water bodies, river basin areas, ridge forests (i.e. near Delhi, near Alwar) and other forest patches record a lower range of land surface temperature (19-31 $\left.{ }^{\circ} \mathrm{C}\right)$. The north-western (western side of Bhiwani and Charki Dadri), western (western side of Rewari), central and south-eastern parts of the NCR, which are predominantly scrubland/fallow land, built-up and barren land, have the highest range of LST $\left(35-42{ }^{\circ} \mathrm{C}\right)$. It is important to mention that areas with the highest summer temperature experienced the lowest monsoon temperature and therefore, the lowest temperature range compared to the summer season due to increased greenness leads to decreased surface albedo, resulting in high-level cooling. During monsoon season, the LST over different LULC is showed in Table 1. The maximum LST is shown in scrubland and agricultural fallow land with an average land surface temperature of $36.80{ }^{\circ} \mathrm{C}$ and minimum over water bodies with a mean land surface temperature of $30.64{ }^{\circ} \mathrm{C}$. The vegetated and agricultural cropland (Kharif crops cropped during south-west monsoon season) that dominates the eastern, north and surrounding the urban peripheries show moderate temperature conditions $\left(31-35^{\circ} \mathrm{C}\right)$.

In all parts of the study area, overall high temperature was recorded in the autumn season compared to the monsoon season (Fig. 5). The land surface temperature pattern, however, is similar to the summer season; however, the temperature was low compared to the summer season. The high land surface temperature pattern of the autumn season is similar to that of the summer season, as high land surface temperature dominance is seen in the outskirts of the city. However, the high land surface temperature areas in the autumn season are relatively smaller than in the summer. During, autumn season the highest and lowest temperature ranges between 26.45 and $38.93{ }^{\circ} \mathrm{C}$ with the mean of $32.96{ }^{\circ} \mathrm{C}$. In autumn, western portions also bear elevated temperature, with the maximum reaches in south-eastern parts of the NCR. Central, northern and eastern NCR are relatively cooler (Fig. 6). Mallick et al. (2012) revealed similar results for LST in the autumn season over Delhi using a Landsat TM image of October 25, 2009. The 10$12{ }^{\circ} \mathrm{C}$ cooler areas were observed around the ridge forests and river basin areas. Because of the prevalence of fallow lands towards the western and south-eastern, the land surface temperature is high, but the incoming radiation is comparatively less compared to the summer season. Scrubland and fallow lands drag the average LST to a higher side (compare to monsoon season), but lower land surface temperature areas tend to be high during the autumn season due to lower heating of other land surfaces. 
NDVI and LST are crucial to understanding the relationships between terrestrial ecosystems and the climate system in an environmentally sensitive area. This research inferred that the relationship between LST and NDVI could help to understand the factors that cause environmental deterioration, significant changes in the carbon cycle of the land-based environment and highlights the mechanisms that control land carbon storage response to climate variability (Zhang et al., 2013; Braswell et al., 1997).
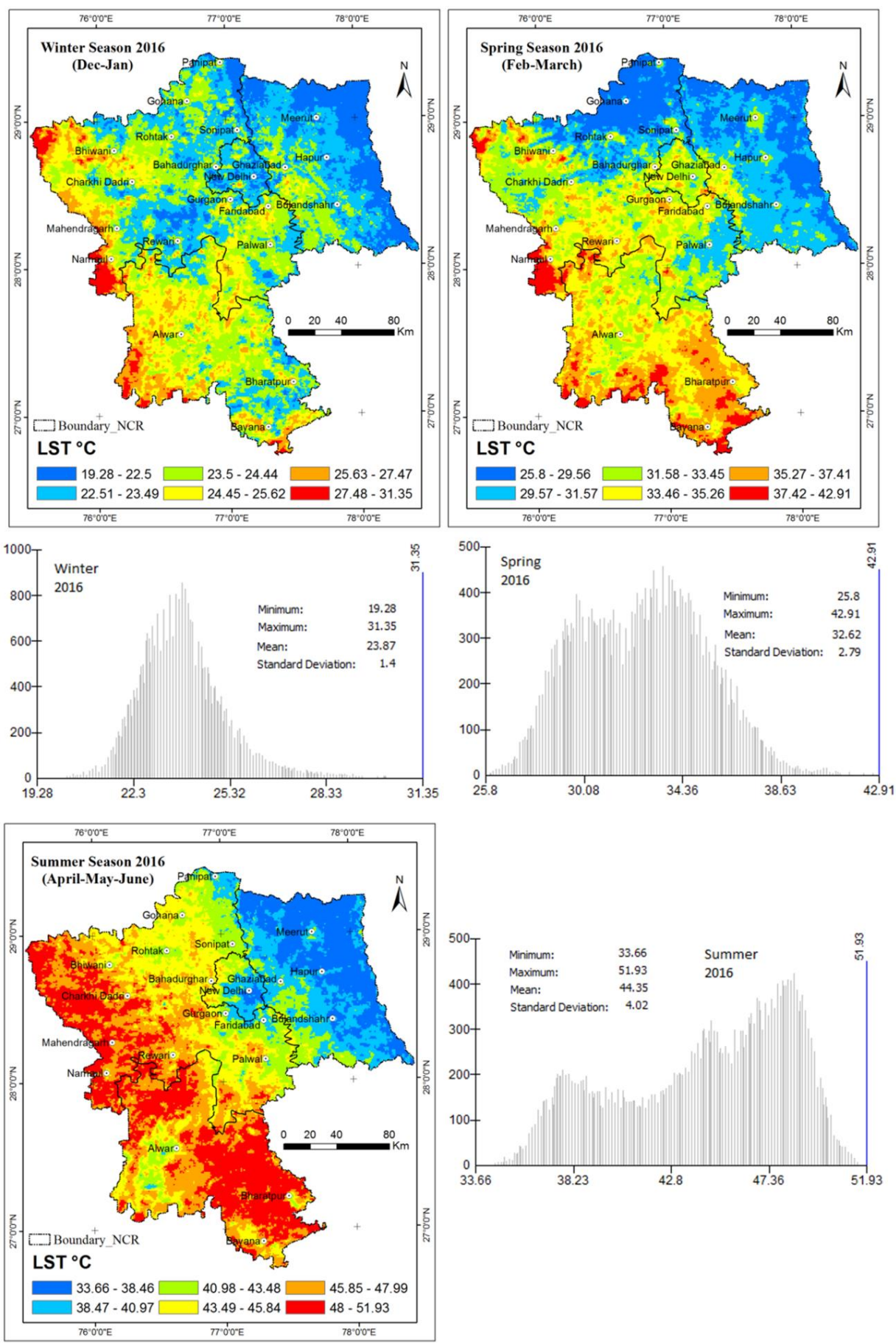

Figure 4. Spatial distribution of seasonal average LST during monsoon and autumn with their histogram (frequency) in 2016 


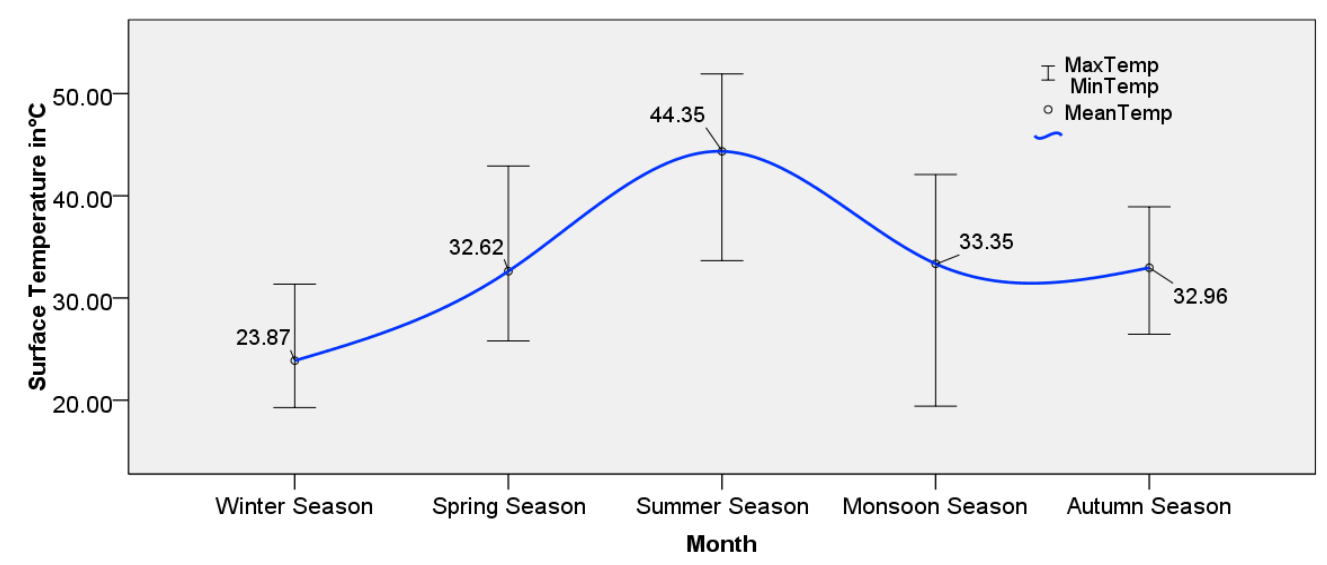

Figure 5. Graphical representation of minimum, maximum and mean LST with different seasons in 2016
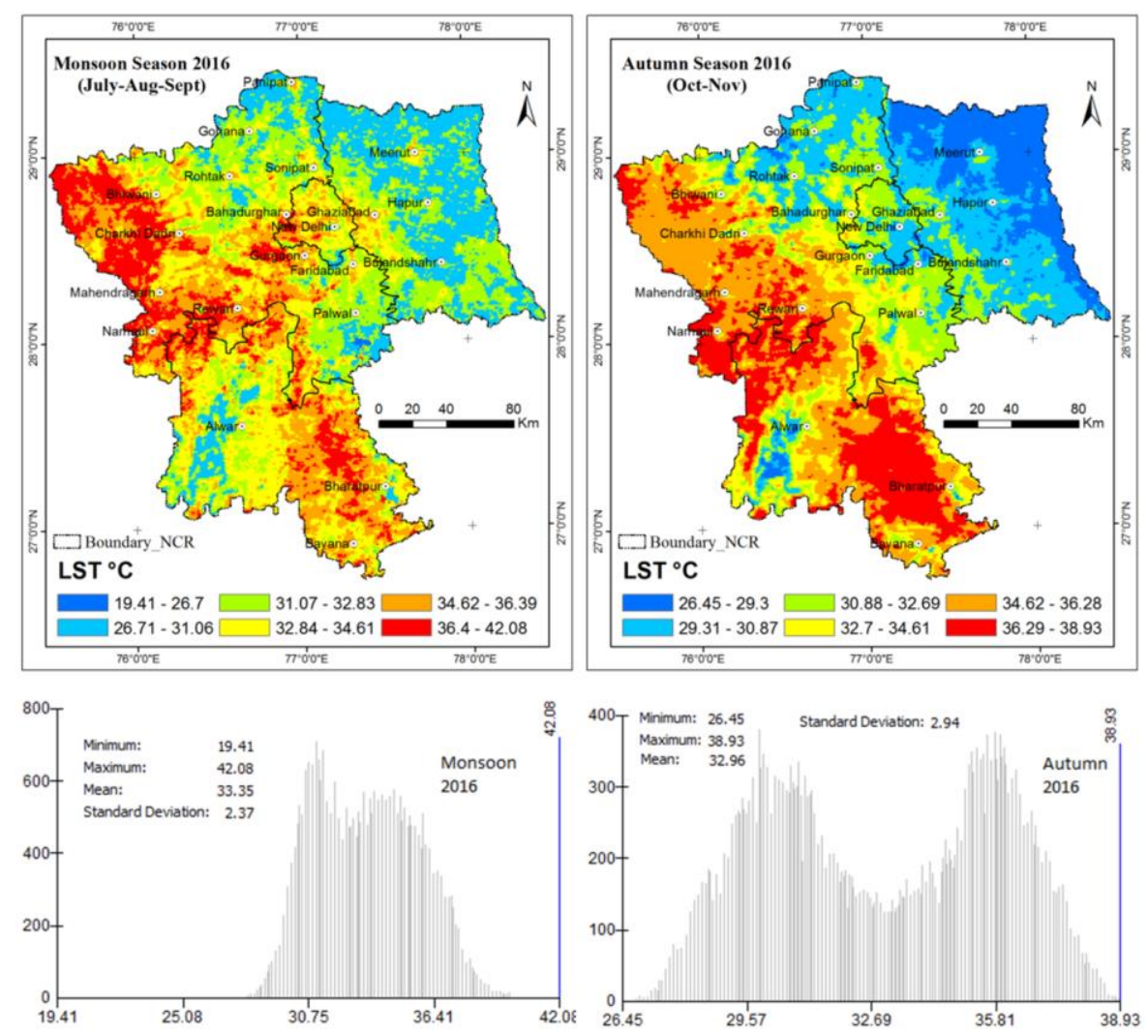

Figure 6. Spatial distribution of seasonal average LST during monsoon and autumn with their histogram (frequency) in 2016

\section{Limitations of research}

In this study, the temporal relationship between land surface temperature mechanics for land use/land cover and vegetation cover (NDVI) were analysed in the National Capital Region (NCR) over the five seasons. The analysis was based on data obtained from January 2016 to December 2016 (short timeframe). However, the short time frame (1-year datasets) may not account satisfactory for the long-term horizon dynamic 
environmental conditions. Moreover, the results are satisfactory for status quo but still can be improved if temporal long-term datasets are considered. Given the importance of long term dynamic environmental factors, future studies need to integrate the long-term data sets to analyze the effects of land surface temperature mechanics for land use/land cover and vegetation cover (NDVI) in the National Capital Region (NCR).

\section{Conclusions}

The studies to understand the seasonal variation of environmental conditions, especially the thermal environment at a regional level lack in India specially in the NCR. Herein, the analysis of the temporal relationship between land surface temperature mechanics for land use/land cover and vegetation cover (NDVI) in the National Capital Region (NCR) over the five seasons has been carried out. The results inferred that the temporal and spatial pattern of LST distribution in the NCR is significantly diverse. The coldest month shows lower LST over all types of land use/land cover, but the highest temperature is accounted for the summer month. For scrubland/fallow land areas and agricultural land, the difference between the maximum and minimum temperature is the highest for all seasons, mainly corresponding to NCR Cities' peripheral areas. This difference is the lowest due to albedo factor for water bodies and vegetation cover. The presence of a perennial river (Ganga river, Yamuna river etc.) flowing through the eastern parts of the NCR has a significant influence to reduce the thermal effects. However, dense built-up area influences rather lead to the increase of the thermal effects. The analysis shows that LST plays a significant role in NDVI related to vegetation vigour and growth in the NCR. The results over the NCR region clearly show NDVI values ranging from 0.229 (April) to 0.627 (August) for all land cover categories, whereas the maximum NDVI value could be seen during Monsoon. The vegetation covers over the NCR region as the mean NDVI values range from 0.398 (Winter) to 0.625 (Monsoon). The study shows that the seasonal distribution of LST needs to be overcome with the high vegetation cover and some other appropriate mitigation measures. One way of mitigating such seasonal peripheral thermal effects could be to adopt better cropping practices in order to minimize the agricultural fallow period and to promote green roofing concepts in urban areas and using porous concrete for construction which might help to mitigate impacts of high LST in urban areas of the NCR.

Future research will concentrate on integrating the long-term data sets to analyze the effects of land surface temperature mechanics for land use/land cover and vegetation cover (NDVI) in the National Capital Region (NCR), India and also to analyze the thermal environment of different NCR Indian cities and comparing their urban thermal behaviour.

Acknowledgements. The authors extend their appreciation to the Deanship of Scientific Research at King Khalid University for funding this work through General Research Project under grant number (R.G.P2/92/41). NASA-USGS personnel at the land DAAC who provided the satellite image are also much appreciated. 


\section{REFERENCES}

[1] Ali, G., Pumijumnong, N., Cui, S. (2017): Valuation and validation of carbon sources and sinks through land cover/use change analysis: the case of Bangkok metropolitan area. Land Use Policy 70: 471-478.

[2] Ali, G., Nitivattananon, V., Mehmood, H., Sabir, M., Sheikh, S. R., Abbas, S. (2012): A synthesis approach to investigate and validate carbon sources and sinks of a mega city of developing country. - Environ. Dev. 4: 54-72.

[3] Beck, P. S. A., Atzberger, C., Hogda, K. A. (2006): Improved monitoring of vegetation dynamics at very high latitudes, a new method using MODIS NDVI. - Remote Sensing of Environment 100: 321-336.

[4] Braswell, B. H., Schimel, D. S., Linder, E., Moore, B. (1997): The response of global terrestrial ecosystems to interannual temperature variability. - Science 238: 870-872.

[5] Chakraborty, S. D., Kant, Y., Mitra, D. (2013): Assessment of land surface temperature and heat fluxes over Delhi using remote sensing data. - J. Environ. Manag. 148: 143-152.

[6] Deng, C., Wu, C. (2013): Examining the impacts of urban biophysical compositions on surface urban heat island: a spectral unmixing and thermal mixing approach. - Remote Sensing of Environment 131: 262-274.

[7] Deng, X. Z., Huang, J. K., Lin, Y. Z., Shi, Q. L. (2013): Interactions between climate, socio-economics, and land dynamics in Qinghai Province, China: a LUCD model-based numerical experiment. - Adv. Meteorol. DOI: 10.1155/2013/297926.

[8] FSI (Forest Survey of India) (2000): The State of Forest Report 1999. - FSI, Government of India, Dehradun.

[9] Gluch, R. Q., Saaroni, D. A., Luvall, J. C. (2006): A multi-scale approach to urban thermal analysis. - Remote Sens. Environ. 104(2): 123-132. http://dx.doi.org/10.1016/j. rse.2006.01.025.

[10] Hang, H. T., Rahman, A. (2018): Characterization of thermal environment over heterogeneous surface of National Capital Region (NCR), India using LANDSAT-8 sensor for regional planning studies. - Urban Climate 24: 1-18. DOI: 10.1016/j.uclim.2018.01.001.

[11] Huete, A. R., Didan, K., Miura, T., Rodriguez, E. P., Gao, X., Ferreira, L. G. (2002): Overview of the radiometric and biophysical performance of the MODIS vegetation indices. - Remote Sensing Environment 83(1-2): 195-213.

[12] Kumari, B., Tayyab, M., Shahfahad, Salman, Mallick, J., Khan, M. F., Rahman, A. (2018): Satellite-driven land surface temperature (LST) using Landsat 5, 7 (TM/ETM+SLC) and Landsat 8 (OLI/TIRS) data and its association with built-up and green cover over urban Delhi, India. - Remote Sensing in Earth Systems Sciences. DOI: 10.1007/s41976-018-0004-2.

[13] Li, Y. Y., Zhang, H., Kainz, W. (2012): Monitoring patterns of urban heat islands of the fast-growing Shanghai metropolis, China: using time-series of Landsat TM/ETM + data. - Int. J. Appl. Earth Obs. Geoinf. 19: 127-138.

[14] Lunetta, R. S., Knight, J. F., Ediriwickrema, J., Lyon, J. G., Worthy, L. D. (2006): Landcover change detection using multi-temporal MODIS NDVI data. - Remote Sensing of Environment 105(2): 142-154.

[15] Mallick, J., Kant, Y., Bharath, B. D. (2008): Estimation of land surface temperature over Delhi using Landsat ETM+. - Journal of Indian Geophysical Union 12(3): 131-140.

[16] Mallick, J., Singh, C. K., Shashtri, S., Rahman, A., Mukherjee, S. (2012): Land surface emissivity retrieval based on moisture index from Landsat TM satellite data over heterogeneous surfaces of Delhi city. - Int. J. Appl. Earth Obs. Geoinf. 19: 348-358.

[17] Mallick, J., Rahman, A., Singh, C. K. (2013): Modeling urban heat islands in heterogeneous land surface and its correlation with impervious surface area by using night-time ASTER satellite data in highly urbanizing city, Delhi-India. - Adv. Space Res. 52: 639-655. 
[18] Mathew, A., Sreekumar, S., Khandelwal, S., Kaul, N., Kumar, R. (2016): Prediction of surface temperatures for the assessment of urban heat island effect over Ahmedabad city using linear time series model. - Energ. Buildings 128: 605-616.

[19] MODIS (1999): MODIS Vegetation Index (MOD 13): Algorithm Theoretical Basis (version 3). - http://modis.gsfc.nasa.gov/data/atbd/atbd_mod13.pdf.

[20] Oke, T. R. (1982): The energetic basis of the urban heat island. - Q. J. R. Meteorol. Soc. 108: 1-24.

[21] Owen, T. W., Carlson, T. N., Gillies, R. R. (1998): An assessment of satellite remotelysensed land cover parameters in quantitatively describing the climatic effect of urbanization. - International Journal of Remote Sensing. DOI: 10.1080/014311698215171.

[22] Pandey, P., Kumar, D., Prakash, A., Kumar, K., Jain, V. K. (2009): A study of the summertime urban heat island over Delhi. - Int. J. Sustain. Sci. Stud. 1: 27-34.

[23] Pandey, P., Kumar, D., Prakash, A., Masih, J., Singh, M., Kumar, S., Jain, V. K., Kumar, K. (2012): A study of urban heat island and its association with particulate matter during winter months over Delhi. - Sci. Total Environ. 414: 494-507.

[24] Potter, C. S., Brooks, V. (1998): Global analysis of empirical relations between annual climate and seasonality of NDVI. - International Journal of Remote Sensing 15: 29212948.

[25] Ren, J., Chen, Z., Zhou, Q., Tang, H. (2008): Regional yield estimation for winter wheat with MODIS-NDVI data in Shandong, China. - International Journal of Applied Earth Observation and Geoinformation 10: 403-413.

[26] Schultz, P. A., Halpert, M. S. (1995): Global correlation of temperature, NDVI and precipitation. - Advance in Space Research 13: 277-280.

[27] Shabana, Ali, G., Bashir, M. K., Ali, H. (2015): Housing valuation of different towns using the hedonic model: a case of Faisalabad City, Pakistan. - Habitat Int. 50: 240-249.

[28] Singh, R. B., Kumar, D. (2012): Remote sensing and GIS for land use/cover mapping and integrated land management: case from the middle Ganga plain. - Front. Earth Sci. 6: 167-176.

[29] Singh, R. B., Grover, A., Zhan, J. (2014): Inter-seasonal variations of surface temperature in the urbanized environment of Delhi using LANDSAT thermal data. - Energies. DOI: 10.3390/en7031811.

[30] Singh, R. P., Roy, S., Kogan, F. (2003): Vegetation and temperature condition indices from NOAA AVHRR data for drought monitoring over India. - Int. J. Remote Sens. 24: 4393-4402.

[31] Streutker, D. R. (2003): Satellite-measured growth of the urban heat island of Houston, Texas. - Remote Sens. Environ. 85: 282-289.

[32] Tongliga, B., Xueming, L., Jing, Z., Yingjia, Z., Shenzhen, T. (2016): Assessing the distribution of urban green spaces and its anisotropic cooling distance on urban heat island pattern in Baotou, China. - Int J Geo-Inform 5(2): 12.

[33] Valsson, S., Bharat, A. (2009): Urban heat island: cause for microclimate variations. Architecture - Time Space \& People 2009(April): 21-25.

[34] Wardlow, B. D., Egbert, S. L., Kastens, J. H. (2007): Analysis of timeseries MODIS 250 $\mathrm{m}$ vegetation index data for crop classification in the U. S. Central Great Plains. - Remote Sensing Environment 108(3): 290-310.

[35] Weng, Q., Yang, S. (2004): Managing the adverse thermal effects of urban development in a densely populated Chinese city. - J. Environ. Manag. 70: 145-156.

[36] Weng, Q. H. (2003): Fractal analysis of satellite-detected urban heat island effect. Photogrammetric Engineering and Remote Sensing 69(5): 555-566.

[37] Xiao, X., Boles, S., Liu, J., Zhuang, D., Frolking, S., Li, C., Salas, W., Moore, B. J. (2005): Mapping paddy rice agriculture in southern China using multi-temporal MODIS images. - Remote Sensing Environment 95(4): 480-492. 
[38] Yuan, F., Bauer, M. E. (2007): Comparison of impervious surface area and normalized difference vegetation index as indicators of surface urban heat island effects in Landsat imagery. - Remote Sens. Environ. 106: 375-386.

[39] Zhang, H., Qi, Z. F., Ye, X. Y., Cai, Y. B., Ma, W. C. (2013): Analysis of land use/land cover change, population shift, and their effects on spatiotemporal patterns of urban heat islands in metropolitan Shanghai, China. - Appl. Geogr. 44: 121-133. 